\title{
Optimization of biogas from corn stover using liquid and solid-state anaerobic digestion
}

\author{
Lukhi Mulia Shitopyta ${ }^{1^{*}}$, Muhammad Hanafi ${ }^{2}$, Yusuf Eko Nugroho ${ }^{3}$ \\ ${ }^{1,2,3}$ Department of Chemical Engineering, Faculty of Industrial Technology, Universitas \\ Ahmad Dahlan \\ Jalan Ringroad Selatan, Kragilan, Bantul, 55164, Yogyakarta, Indonesia \\ ${ }^{*}$ Corresponding author: lukhi.mulia@che.uad.ac.id
}

\begin{abstract}
The shortage of fossil fuel can be minimized by developing renewable energies such as biogas. The raw material of biogas can be derived from corn stover. Biogas was produced under solid-state anaerobic digestion (SS-AD) and liquid anaerobic digestion (L-AD). The objectives of this study were to compare the biogas yield and analyze the $\mathrm{pH}$ value and VS degradation. The results reported that the SS-AD generated a higher biogas yield than L-AD. SS-AD could improve the biogas yield of $71 \%$. Both SS-AD and L-AD had a higher final $\mathrm{pH}$ than the initial $\mathrm{pH}$. Moreover, the VS degradation was proportionate to the biogas yield. The highest VS reduction was achieved on SS-AD.
\end{abstract}

Keywords: anaerobic digestion, biogas, liquid state, solid state, volatile solid, renewable energy

\section{Introduction}

The use of energy from fossil fuel increases continuously, on the contrary, the conventional resources deplete gradually. Due to the issues of an energy shortage, a rule to discover green energy is being developed to minimalize the consumption of fossil oil [1]. Utilization wastes into energy is a helpful solution to diminish greenhouse emission [2]. The anaerobic digestion (AD) decomposes organic materials into biogas as renewable energy. Biogas is a clean gas comprising mainly of methane, carbon dioxide and a trace amount of other gases [3]. Biogas can be utilized as heat and electricity, transportation fuel and digestate for biofertilizer manufacture [4].

Crops have been mainly used as a lignocellulosic biomass feedstock for biogas production through $\mathrm{AD}$ in the current year [5]. Corn stover is plentifully obtainable in Indonesia but it is only left in the fields, causing environmental pollution. The AD process contains four steps, viz. hydrolysis, acidogenesis, acetogenesis and methanogenesis that are performed by microorganisms such as acidogens and methanogens [6]. AD is categorized into liquid (L-AD) and solid-state (SS-AD) concerning total solid (TS) content [7]. L$\mathrm{AD}$ is conducted at TS varies from 0.5 to $15 \%$, whereas SS-AD for TS content of higher than $15 \%$ [8].

The SS-AD has several benefits, e.g. smaller reactor, no need for stirring, higher methane productivity and less water consumption. The digestate of SS-AD can be utilized as a fertilizer [9]. However, SS$\mathrm{AD}$ can lead to feeding and discharging problems, imbalanced mass transfer, and acid inhibition. Conversely, L-AD is simple to control, steady operation stages and produces in high methane production, but some disadvantages are found on $\mathrm{L}-\mathrm{AD}$, for example, larger digester, exaggerated energy through mixing and larger water consumption [10]. The previous studies on biogas production from corn stover have been completed before. However, no study has been investigated to produce biogas from corn stover by L-AD and SS-AD. Therefore, the current study aimed to compare biogas yield on L-AD and SS-AD. 
The $\mathrm{pH}$ and VS reduction were also observed during the digestion.

\section{Material and Methods}

\section{Anaerobic digestion process}

Corn stover is a feedstock was collected from fields in Yogyakarta then it dried and cut into $1-2 \mathrm{~cm}$. The dried corn stover was kept at room temperature before use. Fresh rumen fluid of cow was used as an inoculum to improve the microbe's efficiency. Feedstock and inoculum were mixed with water to adjust TS content of $5 \%$ (L-AD) and 22\% (SS-AD). The mixture was fed to $2 \mathrm{~L}$ digester. Biogas volume was measured every 2 days using the water displacement method.

\section{Analytical method}

This analysis was used to determine TS and volatile solid (VS) content of feedstock and inoculum, respectively. The measurement of TS is to determine the amount of water that be loaded into the digester. To get the initial TS, 25-50 g of sample (corn stover and inoculum) were dried at $103-105^{\circ} \mathrm{C}$ for 1 hour, then dried samples were cooled and weighed until the weight of samples reduced to $4 \%$ or $50 \mathrm{mg}$ from the initial weight.

$$
\% \text { Total solids }=\frac{\mathrm{A}-\mathrm{B}}{\mathrm{C}-\mathrm{B}} \times 100
$$

$\mathrm{A}=$ weight of dried sample and dish (mg)

$\mathrm{B}=$ weight of dish (mg)

$\mathrm{C}=$ weight of wet sample and dish (mg)

VS was measured by igniting the sample in a furnace at $550^{\circ} \mathrm{C}$. Repeat sequence of igniting, cooling and weighing until the weight of samples is less than $4 \%$ or $50 \mathrm{mg}$.

$$
\% \text { Volatile solids }=\frac{A-D}{A-B} \times 100
$$

$\mathrm{A}=$ weight of dried sample and dish (mg)

$\mathrm{B}=$ weight of dish (mg)

$\mathrm{C}=$ weight of wet sample and dish (mg)

$\mathrm{D}=$ weight of ignited sample and dish (mg)

\section{Results and Discussion}

Composition of feedstock and inoculum

The characteristic of materials is displayed in Table 1.

Table 1. Properties of corn stover and rumen fluid

\begin{tabular}{lrr}
\hline Parameters & \multicolumn{2}{c}{ Components } \\
\cline { 2 - 3 } & $\begin{array}{l}\text { Corn } \\
\text { stover }\end{array}$ & \multicolumn{1}{l}{$\begin{array}{l}\text { Rumen } \\
\text { fluid }\end{array}$} \\
\hline Initial TS (\%) & 90.5 & 17.56 \\
Initial VS (\%) & 85 & 12.05 \\
\hline
\end{tabular}

Total solid influences the $\mathrm{pH}$, temperature, and efficiency microbes in the anaerobic digestion [11]. Volatile solid is associated with organic material that is digested by microbes into biogas.

\section{Biogas production}

Biogas yield (L/kg VS) is presented by dividing biogas volume to the initial VS of feedstock. Figure 1 expresses daily biogas yield. Biogas production initiated to produce on day 2 through SS-AD, whereas in $\mathrm{L}-\mathrm{AD}$, biogas volume was generated on day 4. This delay occurred due to the presence of a floating substrate at the bottom of the digester which constrained the transfer of nutrients to the microbes, consequently, the conversion of the substrate was slower and longer.

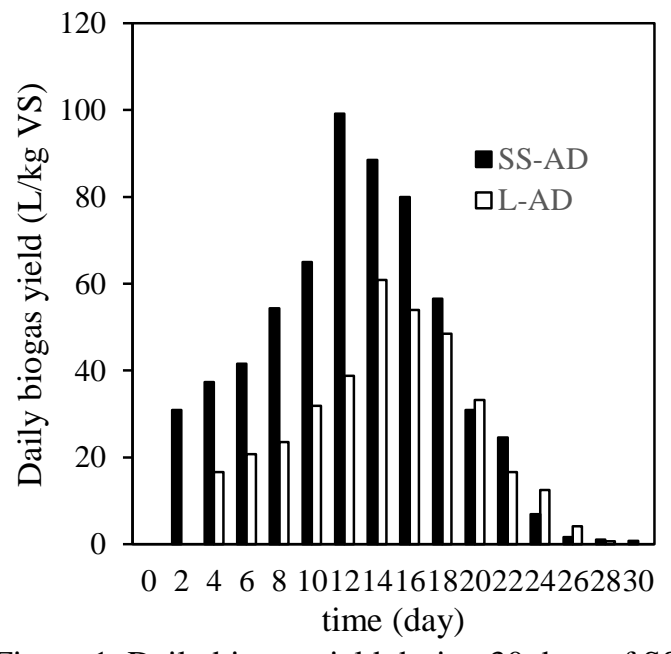

Figure 1. Daily biogas yield during 30 days of SS$\mathrm{AD}$ and $\mathrm{L}-\mathrm{AD}$

The rate of biogas raised gradually until achieving a peak value of $99.15 \mathrm{~L} / \mathrm{kg}$ $\mathrm{VS}$ on day 12 for SS-AD, while the L-AD 
attained a climax yield of $60.90 \mathrm{~L} / \mathrm{kg} \mathrm{VS}$ on day 14. Afterward, biogas production decreased slowly until no measurable biogas volume. This condition happened due to the inhibition of methanogen.

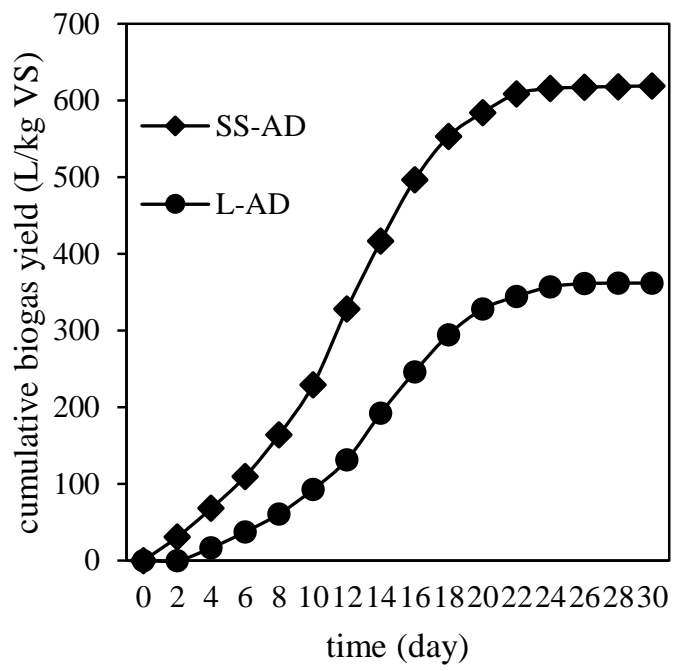

Figure 2. Cumulative biogas yield during digestion of corn stover in SS-AD and L-AD

Figure 2 demonstrates that the accumulative biogas y ields at SS-AD and L-AD were $619.09 \mathrm{~L} / \mathrm{kg}$ VS and 361.94 $\mathrm{L} / \mathrm{kg}$ VS, respectively. This result shows that SS-AD could increase by $71 \%$ of biogas productivity. The higher yield in SSAD was affected by the enhancement of hydrolytic and acidogenic microorganisms in initial phases of digestion which result in a high volatile solid degradation [12]. The Preceding study conducted by Chen et al.(2014) [13] also stated that biogas output from SS-AD was higher than L-AD during the digestion of food waste and green waste.

\section{pH characteristic}

A $\mathrm{pH}$ value is one of the important factors which affects the digestion process. The $\mathrm{pH}$ value affects the growth of methanogen and dissociation of compounds such as ammonia, sulfide and organic acids [14]. The $\mathrm{pH}$ depends on Volatile Fatty Acid (VFA) and buffering capacity. The $\mathrm{pH}$ decline with the increase of VFA production [15]. The optimum $\mathrm{pH}$ for methanogens varies from 6.8 to 7.6 [16]. Microbes in anaerobic digestion have diverse $\mathrm{pH}$ requirements. Acidogens can work at $\mathrm{pH}$ above 5 , while methanogens will inhibit their performance at an acidic condition [17]. A pH lower 6.6 disturbs methanogen activity which leads to toxicity [11].

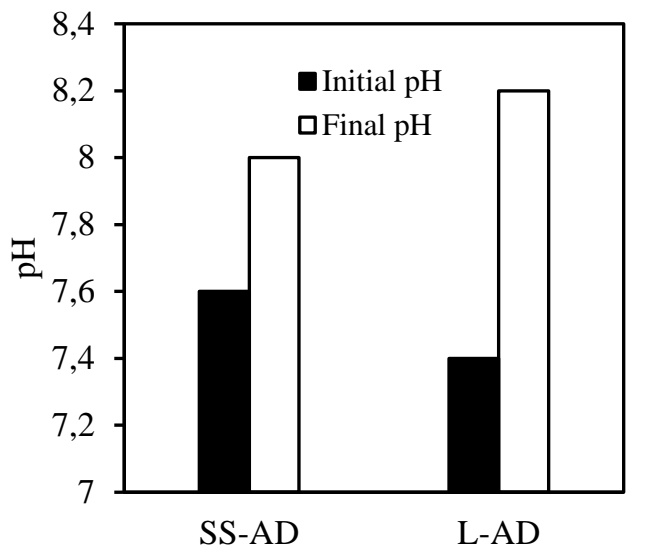

Figure 3. A pH variance during the digestion process

As seen in Figure 3, the initial $\mathrm{pH}$ was at the recommended $\mathrm{pH}$ range but the final $\mathrm{pH}$ was higher than 7.0. The greater $\mathrm{pH}$ indicated that ammonia inhibition occurred in the digester which stopped biogas production [18]. Ammonia inhibition increases with ascending $\mathrm{pH}$ value. Ammonium causes a potassium deficiency of methanogens [19]. The methanogen inhibition can induce the failure of the digester and cease biogas rate production.

\section{Volatile Solid (VS) reduction}

VS is described as the organic part of the total solid [20]. Calculation of VS can be used to manage the AD efficiency [21]. The VS reduction can be calculated by Equation 3 [22].

$\mathrm{VS}_{\text {reduction }}=1-\frac{\mathrm{VS}_{\text {output }} \times\left(1-\mathrm{VS}_{\text {input }}\right)}{\mathrm{VS}_{\text {input }} \times\left(1-\mathrm{VS}_{\text {output }}\right)}$

Where,

$\mathrm{VS}_{\text {reduction }}=$ volatile solid amount of degradation (\%)

$\mathrm{VS}_{\text {input }}=$ volatile solid amount of the input (\%)

$\mathrm{VS}_{\text {output }}=$ volatile solid amount of the output (\%)

The VS reduction is shown in Figure 4. 


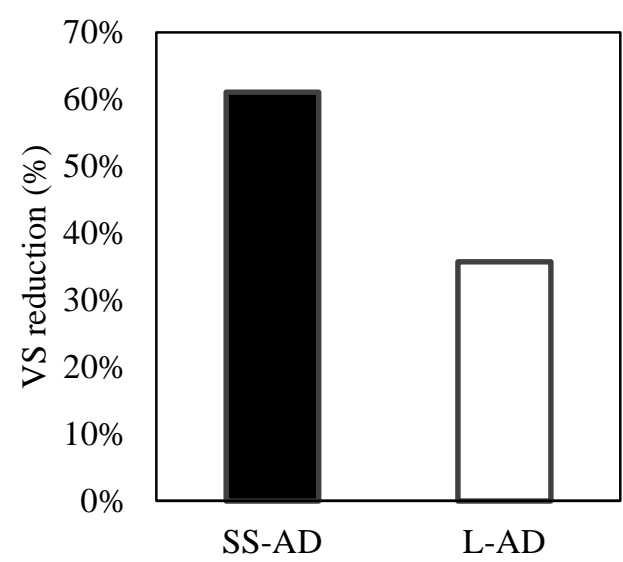

Figure 4. VS reduction during SS-AD and L$\mathrm{AD}$

The highest VS reduction of $61.05 \%$ was obtained on SS-AD. The VS reduction was related to the biogas yield. Consequently, the higher the biogas yield, the higher the VS reduction. L-AD obtained the lower VS reduction due to the low cumulative biogas yield.

\section{Conclusion}

Biogas production through SS-AD produces a higher yield than L-AD. The high rate during $\mathrm{SS}-\mathrm{AD}$ due to the enrichment of microbes at the early stage. The $\mathrm{pH}$ value affects the performance of microbe activity and digester. The final $\mathrm{pH}$ is greater than the initial $\mathrm{pH}$ that indicates ammonia inhibition. The VS reduction is correlated with the biogas yield.

\section{Acknowledgments}

The authors would like to thank LPPM, Universitas Ahmad Dahlan for providing the fundamental research grant (Grant Number: PF-144/SP3/LPPMUAD/IV/2019).

\section{References}

[1] A. A. Pilarska, K. Pilarski, A. Wolna-maruwka, and P. Boniecki, "Use of Confectionery Waste in Biogas Production by," Molecules, vol. 24, no. 37, pp. 1-13, 2018.

[2] D. $\mathrm{Li}$ et al., "Evaluation of relationship between biogas production and microbial communities in anaerobic codigestion," Korean J. Chem. Eng., vol. 35, no. 1, pp. 179-186, 2018.

[3] A. Alkhalidi, M. K. Khawaja, K. A. Amer, A. S. Nawafleh, and M. A. Alsafadi, "Portable biogas digesters for domestic use in Jordanian Villages," Recycling, vol. 4, no. 21, pp. 1-10, 2019.

[4] L. Hagman, A. Blumenthal, M. Eklund, and N. Svensson, "The role of biogas solutions in sustainable biore fi neries," J. Clean. Prod., vol. 172, pp. 3982-3989, 2018.

[5] R. Bedoi, B. Cosi, D. Krajnc, and G. Smoljani, "Green biomass to biogas e A study on anaerobic digestion of residue grass," J. Clean. Prod., vol. 213, pp. 700-709, 2019.

[6] J. Kainthola, A. S. Kalamdhad, and V. V. Goud, "A review on enhanced biogas production from anaerobic digestion of lignocellulosic biomass by different enhancement techniques," Process Biochem., vol. 84, pp. 81-90, 2019.

[7] L. M. Shitophyta, Budiyono, and A. M. Fuadi, "Biogas Production from Rice Straw by Solid-State Anaerobic Digestion," in International Conference of Chemical and Material Engineering(ICCME), 2015, vol. 030025, pp. 1-8.

[8] J. Zhu, Y. Zheng, F. Xu, and Y. Li, "Solid-state anaerobic co-digestion of hay and soybean processing waste for biogas production," Bioresour. Technol., vol. 154, pp. 240-247, 2014.

[9] W. Suksong, P. Kongjan, P. Prasertsan, T. Imai, and S. O-thong, "Optimization and microbial community analysis for production of biogas from solid waste residues of palm oil mill industry by solidstate anaerobic digestion," Bioresour. Technol., vol. 214, pp. 166-174, 2016.

[10] Y. Liu et al., "Change to biogas production in solid-state anaerobic 
digestion using rice straw as substrates at different temperatures," Bioresour. Technol., vol. 293, p. 122066, 2019.

[11] N. Boontian, "Conditions of the Anaerobic Digestion of Biomass," Int. J. Biol. Vet. Agric. Food Eng., vol. 66, no. 9, pp. 960-964, 2014.

[12] D. Brown, J. Shi, and Y. Li, "Comparison of solid-state to liquid anaerobic digestion of lignocellulosic feedstocks for biogas production," Bioresour. Technol., vol. 124, pp. 379-386, 2012.

[13] X. Chen, W. Yan, K. Sheng, and M. Sanati, "Comparison of high-solids to liquid anaerobic co-digestion of food waste and green waste," Bioresour. Technol., vol. 154, pp. 215-221, 2014.

[14] T. Al Seadi et al., Biogas Handbook. Esbjerg: University of Southern Denmark, 2008.

[15] J. Zhu, C. Wan, and Y. Li, "Enhanced solid-state anaerobic digestion of corn stover by alkaline pretreatment," Bioresour. Technol., vol. 101, no. 19, pp. 7523-7528, 2010.

[16] A. K. Jha, J. Li, L. Zhang, Q. Ban, and Y. Jin, "Comparison between Wet and Dry Anaerobic Digestions of Cow Dung under Mesophilic and Thermophilic Conditions," Adv.
Water Resour. Prot., vol. 1, no. 2, pp. 28-38, 2013.

[17] K. M. Kangle, S. V Kore, V. S. Kore, and G. S. Kulkarni, "Recent trends in anaerobic codigestion: review," Univers. J. Environ. Res. Technol., vol. 2, no. 4, pp. 210-219, 2012.

[18] Z. Cui, J. Shi, and Y. Li, "Solid-state anaerobic digestion of spent wheat straw from horse stall," Bioresour. Technol., vol. 102, no. 20, pp. 94329437, 2011.

[19] D. Deublein and A. Steinhauser, Biogas from waste and renewable resources. Weinheim: WILEY-VCH Verlag GmbH \& Co. KGaA, 2008.

[20] E. K. Orhorhoro, P. O. Ebunilo, and G. E. Sadjere, "Experimental Determination of Effect of Total Solid (TS) and Volatile Solid (VS) on Biogas Yield," Am. J. Mod. Energy, vol. 3, no. 6, pp. 131-135, 2017.

[21] S. S. B. Dababat, "Organic Waste Reduction by Co-digestion of Slaughterhouse Wastewater and Domestic Sludge," J. Microb. Biochem. Technol., vol. 11, no. 3, pp. 50-54, 2019.

[22] K. Koch, "Calculating the degree of degradation of the volatile solids in continuously operated bioreactors," Biomass and Bioenergy, vol. 74, pp. 79-83, 2015. 